J. Lake Sci.(湖泊科学), 2022, 34(2): 455-467

DOI 10. 18307/2022. 0208

(c) 2022 by Journal of Lake Sciences

\title{
太湖沿岸区浅层底泥重金属污染分析及生态风险评价"
}

\author{
陆志华**, 蔡 梅, 王元元, 钱 旭, 潘明祥 \\ (太湖流域管理局水利发展研究中心, 上海 200434)
}

\begin{abstract}
摘 要: 近年来太湖底泥重金属污染越来越受到各方关注. 为了解太湖沿岸区底泥重金属污染状况,基于 2018 年太湖全 湖污染底泥勘察项目中重金属监测数据, 对梅梁湖、竺山湖、西部沿岸区、南部沿岸区、东太湖、贡湖 6 个太湖沿岸湖区浅 层( $0 \sim 30 \mathrm{~cm}$ 深度区间) 底泥中 $\mathrm{Hg} 、 \mathrm{Cd} 、 \mathrm{As} 、 \mathrm{~Pb} 、 \mathrm{Cu} 、 \mathrm{Zn} 、 \mathrm{Cr} 、 \mathrm{Ni} 8$ 种重金属元素含量进行分析, 运用潜在生态风险指数法及 空间插值分析方法对底泥重金属污染生态风险进行评价, 并对底泥重金属来源进行初步分析. 结果表明, 太湖沿岸区浅 层底泥中重金属分布具有明显的空间异质性, 竺山湖、西部沿岸区、贡湖、梅梁湖等湖区重金属含量较高, 南部沿岸区、东 太湖重金属含量相对较低; 各个湖区的 $\mathrm{Cd} 、 \mathrm{~Pb} 、 \mathrm{Cu} 、 \mathrm{Zn} 、 \mathrm{Ni}$ 含量, 竺山湖的 $\mathrm{Hg} 、 \mathrm{As} 、 \mathrm{Cr}$ 含量, 贡湖的 $\mathrm{As} 、 \mathrm{Cr}$ 含量, 南部沿岸区 的 As 含量以及梅梁湖的 $\mathrm{Cr}$ 含量均高于背景值; $0 \sim 30 \mathrm{~cm}$ 不同深度区间内底泥重金属含量越往表层相对越高. 潜在生态 风险指数法评价结果表明, $0 \sim 30 \mathrm{~cm}$ 深度区间内底泥重金属严重污染区域 (重金属综合潜在生态风险指数 $R I \geqslant 300$ 的区 域) 主要分布在西部沿岸区中部 (萃渎港至乌溪港近岸侧)、竺山湖北部、贡湖北部 (望虞河人河口附近), 面积分别为 $104.54 、 10.80 、 6.89 \mathrm{~km}^{2}$, 合计约 $122.23 \mathrm{~km}^{2}$; $\mathrm{Cd}$ 和 $\mathrm{Hg}$ 是主要的重金属生态风险贡献因子、且毒性较强, 西部沿岸区、贡湖 主要表现为 $\mathrm{Cd}$ 污染,竺山湖主要表现为 $\mathrm{Cd} 、 \mathrm{Hg}$ 复合污染,且西部沿岸区的 $\mathrm{Cd}$ 污染最为严重. 重金属源分析结果表明,太 湖沿岸区浅层底泥中 $\mathrm{Zn} 、 \mathrm{Cu} 、 \mathrm{Cr} 、 \mathrm{Ni} 、 \mathrm{Hg} 、 \mathrm{~Pb} 、 \mathrm{As}$ 具有相似的来源, 可能主要来自于工业污染, $\mathrm{Cd}$ 可能主要来自于农业污染. 研究结果可为太湖底泥重金属污染防治提供一定参考和基础数据支撑.
\end{abstract}

关键词: 太湖;底泥; 重金属;污染特征;潜在生态风险指数;风险评价;源解析

\section{Heavy metal pollution analysis and ecological risk assessment of shallow sediments in the coastal area of Lake Taihu*}

Lu Zhihua** , Cai Mei, Wang Yuanyuan, Qian Xu \& Pan Mingxiang

( Water Conservancy Development Research Center of Taihu Basin Authority of Ministry of Water Resources, Shanghai 200434, P.R.China)

Abstract: Lake Taihu is the third-largest lake in China, which is located at the junction of Shanghai City, Jiangsu Province and Zhejiang Province. Lake Taihu and Taihu Basin play a crucial role in the implementation of the national strategy of the integrated development of the Yangtze River Delta region. To characterize the pollution characteristics of heavy metals in shallow sediments in the coastal area of Lake Taihu, the monitoring test data for heavy metals of 230 sediment samples at $0-10 \mathrm{~cm}$ depth, 159 sediment samples at 10-20 cm depth, and 115 sediment samples at 20-30 cm depth were collected which were from the investigation project of polluted sediments in Lake Taihu in the year of 2018. The contents of eight heavy metal elements ( $\mathrm{Hg}, \mathrm{Cd}, \mathrm{As}, \mathrm{Pb}, \mathrm{Cu}, \mathrm{Zn}$, $\mathrm{Cr}$ and $\mathrm{Ni}$ ) in the samples which in Meiliang Bay, Zhushan Bay, Western Coastal Area of Lake Taihu, Southern Coastal Area of Lake Taihu, East Lake Taihu and Gonghu Bay were analyzed. The potential ecological risk index method and spatial interpolation analysis method were applied to evaluate the ecological risk of heavy metal pollution in sediments, and the sources of heavy metals in sediments were preliminarily analyzed. The results showed that the distribution of heavy metals in shallow sediments had evident spatial heterogeneity. The heavy metals' contents in Zhushan Bay, Western Coastal Area of Lake Taihu, Gonghu Bay and Meiliang Bay were higher than those in the Southern Coastal Area of Lake Taihu and Eastern Lake Taihu. The contents of $\mathrm{Cd}, \mathrm{Pb}, \mathrm{Cu}, \mathrm{Zn}$ and Ni in each lake area, the contents of $\mathrm{Hg}$, As and Cr in Zhushan Bay, the contents of As and Cr in Gonghu Bay, the content of

* 2021-06-24 收稿; 2021-08-27 收修改稿.

国家重点研发计划项目 (2018YFC0407205) 资助.

** 通信作者;E-mail: luzhihua2008@qq.com. 
As in the Southern Coastal Area of Lake Taihu, the content of Cr in Meiliang Bay were higher than the background value. The heavy metals contents in sediments in different depths of $0-30 \mathrm{~cm}$ had a rise from its bottom to its surface. The potential ecological risk assessment results presented that the seriously polluted area of heavy metals in sediments at $0-30 \mathrm{~cm}$ depth which heavy metals ecological risk index $R I \geqslant 300$ were mainly distributed in the central part of the Western Coastal Area of Lake Taihu (the nearshore side from Jiaodu River to Wuxi River), the northern part of Zhushan Bay, the northern part of Gonghu Bay. The distribution area was $104.54 \mathrm{~km}^{2}, 10.80 \mathrm{~m}^{2}$ and $6.89 \mathrm{~m}^{2}$ respectively, with a total area of $122.23 \mathrm{~km}^{2}$. Cd and $\mathrm{Hg}$ were the main heavy metal ecological risk contributors with strong toxicity. The Western Coastal Area of Lake Taihu and Gonghu Bay were mainly polluted by Cd, Zhushan Bay was mainly polluted by Cd and Hg. The Cd pollution in the Western Coastal Area of Lake Taihu was the most serious. The heavy metals source analysis results demonstrated that the $\mathrm{Zn}, \mathrm{Cu}, \mathrm{Cr}, \mathrm{Ni}, \mathrm{Hg}, \mathrm{Pb}$ and As in shallow sediments in the coastal area of Lake Taihu have similar sources, which may mainly come from industrial pollution. Moreover, the Cd may come from agricultural pollution. The research results can provide references and basic data supports for the prevention and control of heavy metal pollution in the sediments of Lake Taihu.

Keywords: Lake Taihu; sediments; heavy metals; pollution characteristics; potential ecological risk assessment; risk assessment; source analysis

湖泊底泥是重金属、营养盐等污染物质的蓄积地 ${ }^{[1]}$. 来自河流输人、大气沉降等的污染物质与悬浮颗 粒物结合进入湖泊中, 通过沉降作用, 蓄积于湖泊底泥的表层 ${ }^{[2]}$. 重金属作为典型的累积性污染物, 其显著 的生物毒性和持久性, 对生态环境构成潜在威胁 ${ }^{[3]}$. 重金属通过吸附、络合、沉淀等作用而沉积到底泥中, 同 时与水相保持一定的动态平衡, 当环境条件发生变化时, 重金属极易被释放到间隙水中, 在扩散作用下最终 释放到湖泊水体中, 引起 “二次污染” ${ }^{[4]}$, 成为湖泊水生生态系统的重要污染内源 ${ }^{[5]}$. 底泥中重金属能够较好 地反映水体污染状态以及水生态环境演变过程,一直以来都是科学研究的重点对象 ${ }^{[6]}$, 南四湖 ${ }^{[1]}$ 、洞庭 湖 $^{[7]}$ 、巢湖 ${ }^{[8]}$ 、西氿 ${ }^{[9]}$ 、太湖等湖泊底泥中重金属污染状况均备受关注. 因此,开展湖泊底泥重金属污染状况 分析,对于湖泊生态环境质量研究、湖泊污染底泥生态清淤等具有重要意义.

太湖是我国第三大淡水湖,水域面积 $2338 \mathrm{~km}^{2}$, 平均水深 $1.89 \mathrm{~m}$, 属典型的平原浅水湖泊. 太湖以其独 特的优越自然条件在维系和支撑着自身及长三角生态平衡, 其生态功能作用受损也将影响长三角可持续发 展 ${ }^{[10]}$. 从 1980s 开始, 太湖周边区域的人口数量增加和经济快速发展, 导致大量未经处理或部分处理的工农 业和生活污水排放造成太湖重金属污染. 经过多年治理, 流域污染有所好转, 但底泥中重金属污染仍然是威 胁太湖生态环境的主要问题之一 ${ }^{[11]}$. 已有许多研究报道了太湖底泥重金属污染状况. 太湖底泥重金属污染

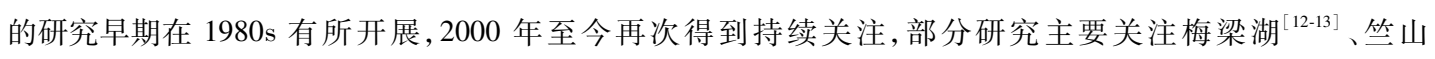
湖 $^{[2,14]}$ 、东太湖 ${ }^{[3]}$ 、㔻湖 ${ }^{[15]}$ 等局部湖区, 也有一些研究达到全湖尺度, 但是普遍存在采样点稀疏的情况, 且大 部分研究并未进行分层研究; 综合诸多研究 ${ }^{[16-26]}$ 发现,梅梁湖、竺山湖、西部沿岸区、贡湖等湖区重金属污染 较为严重, 且 $\mathrm{Hg} 、 \mathrm{Cd} 、 \mathrm{As} 、 \mathrm{~Pb} 、 \mathrm{Cu} 、 \mathrm{Zn} 、 \mathrm{Cr} 、 \mathrm{Ni} 8$ 种重金属是太湖底泥最受关注的重金属元素, 其中 $\mathrm{Cd}$ 是潜在生 态风险的主要贡献者. 无锡市环境保护局和中国科学院南京地理与湖泊研究所 ${ }^{[25]}$ 于 $1980-1981$ 年组织开 展了太湖环境质量调查研究, 发现部分河口及梅梁湖地区有轻微的重金属污染. 中国科学院南京地理与湖 泊研究所 ${ }^{[26]}$ 于 1988 年再次对太湖底泥重金属污染进行了调查, 发现无锡、苏州和长兴沿岸是重金属的主要 污染区. Qu 等 ${ }^{[16]}$ 基于 2000 年 2 月全湖 13 个点位的底泥数据、王海等 ${ }^{[22]}$ 基于 2000 年 11 月全湖 12 个点位 数据、袁旭音等 ${ }^{[23]}$ 基于 2000 年全湖 44 个点位数据, 分析发现梅梁湖是太湖底泥重金属污染最严重的地区, $\mathrm{As} 、 \mathrm{Hg} 、 \mathrm{Cu} 、 \mathrm{Zn} 、 \mathrm{Ni}$ 等重金属含量在太湖北部湖区较高. 尹洪斌等 ${ }^{[27]}$ 基于全湖 2007 年 8-9 月 206 个点位数 据, 发现五里湖、贡湖、西部、南部湖区的底泥重金属污染程度较高,其他湖区污染程度中等. 陈春宵等 ${ }^{[28]}$ 基 于 2009 年 5 月全湖 37 个点位数据、袁和忠等 ${ }^{[5]}$ 基于 2009 年 11 月全湖 6 个点位数据、刘恩峰等 ${ }^{[29]}$ 基于全湖 2009 年 37 个点位数据, 分析发现太湖浅层底泥中重金属含量高于背景值, 北部湖区如竺山湖重金属污染程 度显著高于其他湖区, 北湖湖区的潜在生态风险也相对更高. 秦延文等 ${ }^{[30]}$ 基于 2011 年 8-9 月全湖 30 个点 位数据, 发现太湖浅层底泥中 $\mathrm{Cd} 、 \mathrm{~Pb} 、 \mathrm{Cu} 、 \mathrm{Zn} 4$ 种重金属元素均有一定程度的富集, 其中 $\mathrm{Cd}$ 的富集程度最为 严重, 且 $\mathrm{Cd}$ 为最主要的污染元素. Niu 等 $^{[31]}$ 基于 2013 年 8 月全湖 59 个点位数据, 发现重金属含量较高的 分布区域主要集中在竺山湖、梅梁湖、贡湖. 任杰等 ${ }^{\left[{ }^{[17]}\right.}$ 基于 2015 年 10 月全湖 21 个点位数据, 发现 $\mathrm{Cd}$ 具有 
较重生态风险,竺山湖和梅梁湖的重金属污染情况最严重. 邓延慧等 ${ }^{[20]}$ 基于 2020 年 3 月全湖 20 个点位数 据, 发现 $\mathrm{Cr} 、 \mathrm{~Pb} 、 \mathrm{Cu} 、 \mathrm{Zn}$ 平均含量均高于背景值, 最高值均位于竺山湖心. 因此, 总体来看, 西部沿岸区、竺山 湖、梅梁湖、贡湖等太湖沿岸区域重金属污染较为严重,这种空间分布特征主要与周边地区经济发展和人类 生活关系密切, 湖湾周边地区经济发展较快, 居住人口众多, 因而污染状况显得愈加明显.

为掌握太湖沿岸区最新的底泥重金属污染状况及生态风险, 本文基于水利部太湖流域管理局最新组织 的太湖全湖污染底泥勘察项目中太湖沿岸区 $0 \sim 30 \mathrm{~cm}$ 深度区间浅层底泥重金属 $(\mathrm{Hg} 、 \mathrm{Cd} 、 \mathrm{As} 、 \mathrm{~Pb} 、 \mathrm{Cu} 、 \mathrm{Zn} 、 \mathrm{Cr} 、$ $\mathrm{Ni}$ ) 含量数据, 分析太湖浅层底泥重金属含量分布特征, 运用潜在生态风险指数法及空间插值分析方法对重 金属污染生态风险进行评价,运用主成分分析法和相关性分析法对重金属来源进行初步分析, 以期为太湖 底泥重金属污染防治提供一定参考和基础数据支撑.

\section{1 材料与方法}

\section{1 底泥样品数据基本情况}

水利部太湖流域管理局于 2018一-2019 年组织中水北方勘测设计研究有限责任公司和广东地质实验测 试中心完成了太湖水下地形测量及污染底泥勘察项目. 本文采用该项目中 $0 \sim 30 \mathrm{~cm}$ 深度区间底泥重金属含 量数据开展分析. 该项目对太湖底泥污染较严重的重点区域 (梅梁湖、竺山湖、西部沿岸区、南部沿岸区、东 太湖、贡湖 6 个沿岸湖区) 进行采样, 对于东部沿岸区及湖心区基本未进行采样. 按照 $2 \mathrm{~km} \times 2 \mathrm{~km}$ 正方形网 格布设采样点, 主要人湖河道河口在沿水流方向向湖区 $1 \mathrm{~km}$ 处布设采样点, 沿岸区一般沿距岸线 $50 \mathrm{~m} 、 1.5$ $\mathrm{km}$ 布设采样线, 在采样线上间隔 $1.5 \mathrm{~km}$ 布设采样点 (图 1). 调查取样时间为 2018 年 10-11 月, 使用箱式 采样器采集 $30 \mathrm{~cm}$ 深度内的 3 层样品, $0 \sim 10 、 10 \sim 20 、 20 \sim 30 \mathrm{~cm}$ 深度区间分别布设采样点 $230 、 159 、 115$ 个, 将采集的底泥样品依次装人专用的容器中送至实验室进行分析, 重金属测试指标包含 $\mathrm{Hg} 、 \mathrm{Cd} 、 \mathrm{As} 、 \mathrm{~Pb} 、 \mathrm{Cu} 、$ $\mathrm{Zn} 、 \mathrm{Cr} 、 \mathrm{Ni}$, 其中 $\mathrm{Cd} 、 \mathrm{~Pb} 、 \mathrm{Cu} 、 \mathrm{Zn} 、 \mathrm{Cr} 、 \mathrm{Ni}$ 含量采用电感耦合等离子体质谱仪 (ICP-MS) 测定, Hg、As 含量采用原 子荧光光谱仪 (AFS) 测定. 采样测试过程严格实施 “采样一保存-运输-测试” 的全流程质量控制措施, 使各 项数据质量能够得到有效保证, 满足《水环境监测规范》(SL219-2013) 等相关要求.

\section{2 空间插值方法}

本文运用 ArcGIS 软件, 采用 GIS 空间插值法对有限的离散的实测数据点进行插值, 实现空间数据的连 续化, 分析太湖底泥重金属含量的空间分布特征. 空间插值法被广泛应用于气温、降雨、污染物浓度等方面, 常用的空间插值法有反距离加权、全局多项式、局部多项式、普通克里金及径向基函数等. 本文采用径向基 函数法进行空间插值 (网格尺寸为 $200 \mathrm{~m} \times 200 \mathrm{~m}$ ), 总体拟合度较高, 在极值区没有明显偏差.

\section{3 重金属污染评价方法}

底泥重金属污染评价方法主要有单因子评价法、内梅罗污染指数法、污染负荷指数法、地累积指数法、 富集系数法、潜在生态风险指数法等. 潜在生态风险指数法是瑞典科学家 Hakanson 提出的一种综合考虑重 金属毒性、评价区域对重金属污染的敏感性、重金属区域背景值差异, 可以综合反映底泥中重金属潜在生态 影响的评价方法 ${ }^{[32]}$, 在底泥重金属污染评价中广泛应用 ${ }^{[33-34]}$, 也是环境保护部制定的《湖泊河流环保疏浚 工程技术指南 (试行)》中推荐的重金属污染底泥鉴别评估标准的制定方法. 因此,本文采用潜在生态风险指 数法对太湖底泥重金属污染进行评价. 计算公式如下:

1) 单项重金属污染指数:

$$
C_{f}=C_{i} / C_{n}
$$

式中, $C_{f}$ 为重金属 $i$ 的污染指数, $C_{i}$ 为重金属 $i$ 的实测含量, $C_{n}$ 为重金属 $i$ 的评价参比值, 即为底泥重金属的 背景值, 本文选用文献 $[16,27,35]$ 提出的太湖底泥重金属含量背景值, 见表 1 .

2) 单项重金属 $i$ 的潜在生态风险指数:

$$
E_{r}=T_{r} \cdot C_{f}
$$

式中, $E_{r}$ 为单项重金属 $i$ 的潜在生态风险指数, $T_{r}$ 为重金属毒性响应系数, 反映重金属的毒性水平及生物对 重金属污染的敏感程度,各重金属的 $T_{r}$ 见表 1. 


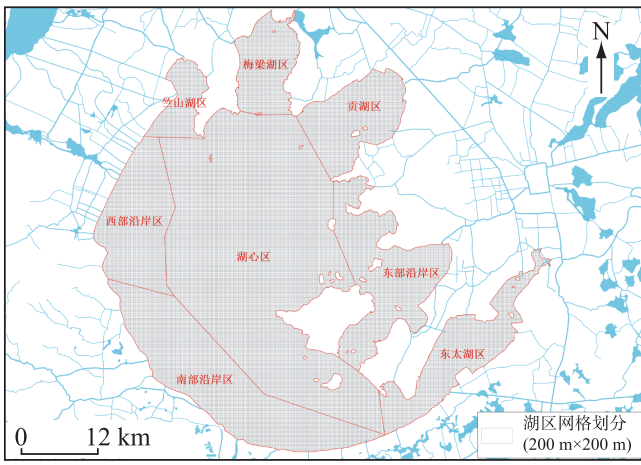

太湖湖区划分

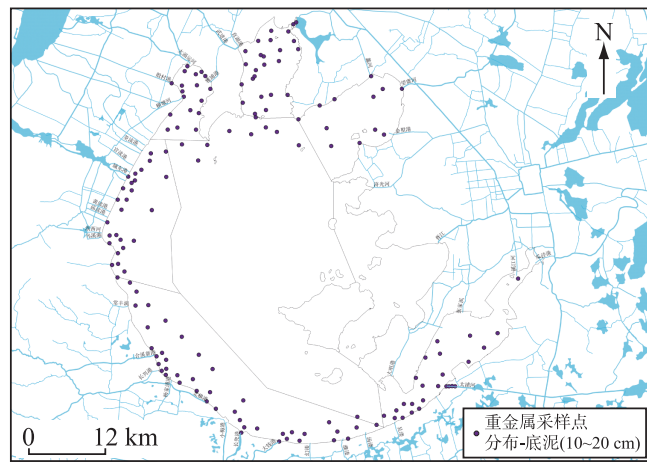

10 20 cm深度底泥采样点

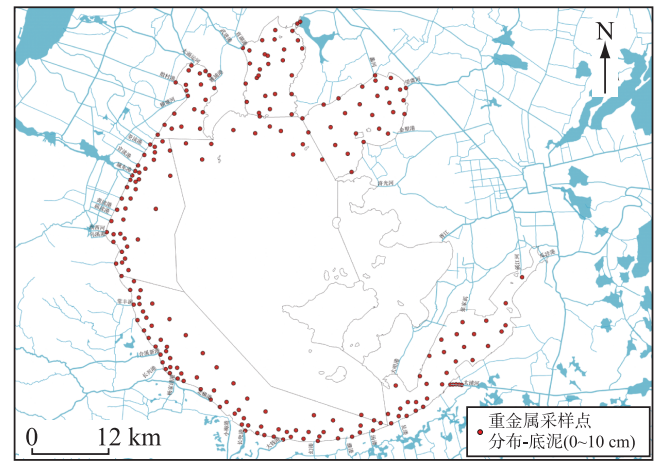

$0 \sim 10 \mathrm{~cm}$ 深度底泥采样点

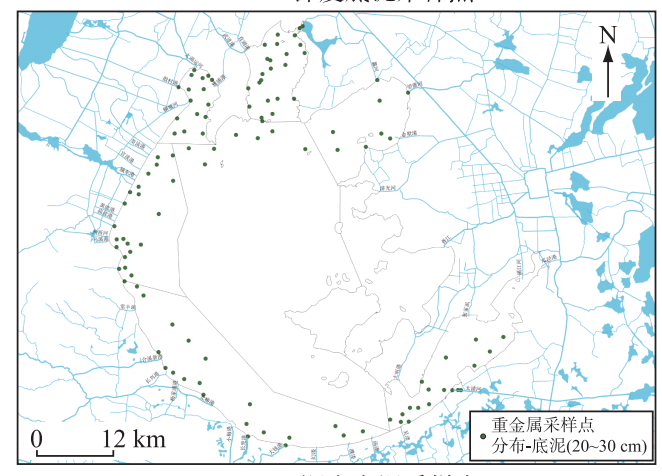

20 30 cm深度底泥采样点

图 1 太湖湖区划分及不同深度底泥采样点分布

Fig. 1 Lake area division of Lake Taihu and distribution of sediment samples at different depths

表 1 太湖底泥重金属背景值及重金属毒性响应系数

Tab.1 Background values and toxicity response coefficients of heavy metals in sediments of Lake Taihu

\begin{tabular}{cccccccccc}
\hline & \multicolumn{7}{c}{ 重金属元素 } \\
\cline { 2 - 9 }$y$ & $\mathrm{Hg}$ & $\mathrm{Cd}$ & $\mathrm{As}$ & $\mathrm{Pb}$ & $\mathrm{Cu}$ & $\mathrm{Zn}$ & $\mathrm{Cr}$ & $\mathrm{Ni}$ \\
\hline 背景值 $C_{n} /(\mathrm{mg} / \mathrm{kg})$ & 0.11 & 0.27 & 9.4 & 15.7 & 18.9 & 59 & 79.3 & 19.5 \\
重金属毒性响应系数 $T_{r}$ & 40 & 30 & 10 & 5 & 5 & 1 & 2 & 5 \\
\hline
\end{tabular}

3) 多项重金属的综合潜在生态风险指数 $R I$ 为单项重金属潜在生态风险指数之和,即 :

$R I=\sum E_{r}$

$E_{r} 、 R I$ 和潜在生态风险等级划分见表 2. 另《湖泊河流环保疏浚工程技术指南 (试行)》提出,工程区重金 属污染底泥的疏浚控制值 $R I \geqslant 300$. 因此, 本文以 $R I \geqslant 300$ 作为底泥属于重金属严重污染的鉴别标准.

\section{4 重金属源解析方法}

主成分分析法 ${ }^{[34]}$ 、相关性分析法 ${ }^{[36]}$ 是底泥重金属来源分析常用的方法. 主成分分析法采用数学降维或 特征提取方法, 将原来众多的且具有一定相关性的原始变量进行线性变换, 提取出数目较少且彼此间互不 相关的重要变量,使用较少的有代表性的因子来解释众多变量的主要信息,并推测有关污染源的信息 ${ }^{[37]}$. 一般认为, 底泥中重金属元素含量之间及其之间的比率具有相对的稳定性, 当底泥的来源相似或相同时, 其 各元素之间具有显著的相关性,因此通过重金属元素之间的相关分析, 可以确定重金属在底泥中的含量变 化的控制因素, 反映不同元素间沉积环境的相似性和受人为影响程度的强弱 ${ }^{[38]}$. 本文使用 SPSS 18 软件进 行主成分分析、相关性分析. 
表 2 重金属单项和综合潜在生态风险指数等级划分

Tab.2 Classification of potential ecological risk index of heavy metals

\begin{tabular}{|c|c|c|c|}
\hline \multicolumn{2}{|c|}{ 单项重金属潜在生态风险指数 $E_{r}$} & \multicolumn{2}{|c|}{ 综合潜在生态风险指数 $R I$} \\
\hline 阈值区间 & 程度分级 & 阈值区间 & 程度分级 \\
\hline$E_{r}<40$ & 低风险 & $R I<150$ & 低风险 \\
\hline $40 \leqslant E_{r}<80$ & 中风险 & $150 \leqslant R I<300$ & 中风险 \\
\hline $80 \leqslant E_{r}<160$ & 较高风险 & $300 \leqslant R I<600$ & 较高风险 \\
\hline $160 \leqslant E_{r}<320$ & 高污染 & $600 \leqslant R I<1200$ & 很高风险 \\
\hline$E_{r} \geqslant 320$ & 很高污染 & $R I \geqslant 1200$ & 极高风险 \\
\hline
\end{tabular}

\section{2 结果与讨论}

\section{1 重金属含量分布特征分析}

对太湖沿岸区 0 30 cm 不同深度区间 $\mathrm{Hg} 、 \mathrm{Cd} 、 \mathrm{As} 、 \mathrm{~Pb} 、 \mathrm{Cu} 、 \mathrm{Zn} 、 \mathrm{Cr} 、 \mathrm{Ni} 8$ 种重金属含量进行统计(图 2), 发 现不同湖区不同重金属的含量分布情况不尽相同、具有明显的空间异质性. 从不同湖区来看, (1) 竺山湖的 $\mathrm{Hg} 、 \mathrm{As} 、 \mathrm{~Pb} 、 \mathrm{Cu} 、 \mathrm{Zn} 、 \mathrm{Cr} 、 \mathrm{Ni} 7$ 种重金属含量均高于其他湖区、 $\mathrm{Cd}$ 含量在各湖区中居第 2 位, 且 8 种重金属含量 均高于太湖平均背景值. $0 \sim 30 \mathrm{~cm}$ 底泥内 $\mathrm{Hg}$ 含量在 $0.05 \sim 0.28 \mathrm{mg} / \mathrm{kg}$ 范围内, 平均含量为 $0.16 \mathrm{mg} / \mathrm{kg}$, 超过 背景值的 $42.4 \%$; As 含量在 $6.19 \sim 24.10 \mathrm{mg} / \mathrm{kg}$ 范围内, 平均含量为 $14.33 \mathrm{mg} / \mathrm{kg}$, 超过背景值的 $52.5 \%$; Pb 含量在 $21.60 \sim 60.80 \mathrm{mg} / \mathrm{kg}$ 范围内, 平均含量为 $44.53 \mathrm{mg} / \mathrm{kg}$, 超过背景值的 1.8 倍, $\mathrm{Cu}$ 含量在 27.90 211.00 $\mathrm{mg} / \mathrm{kg}$ 范围内, 平均含量为 $101.23 \mathrm{mg} / \mathrm{kg}$, 超过背景值的 4.4 倍; $\mathrm{Zn}$ 含量在 $89.70 \sim 565.00 \mathrm{mg} / \mathrm{kg}$ 范围内, 平 均含量为 $293.00 \mathrm{mg} / \mathrm{kg}$, 超过背景值的 4.0 倍; $\mathrm{Cr}$ 含量在 $65.10 \sim 412.00 \mathrm{mg} / \mathrm{kg}$ 范围内, 平均含量为 193.67 $\mathrm{mg} / \mathrm{kg}$, 超过背景值的 1.4 倍; $\mathrm{Ni}$ 含量在 $35.20 \sim 170.00 \mathrm{mg} / \mathrm{kg}$ 范围内, 平均含量为 $97.70 \mathrm{mg} / \mathrm{kg}$, 超过背景值 的 4 倍, $\mathrm{Cd}$ 含量在 $0.17 \sim 1.55 \mathrm{mg} / \mathrm{kg}$ 范围内, 平均含量为 $0.84 \mathrm{mg} / \mathrm{kg}$, 超过背景值的 2.1 倍. (2) 梅梁湖主要 表现为 $\mathrm{Ni}$ 含量在各湖区中居第 2 位, $\mathrm{Pb} 、 \mathrm{Cu} 、 \mathrm{Zn} 、 \mathrm{Cr}$ 含量在各湖区中居第 3 位, 且 $\mathrm{Cd} 、 \mathrm{~Pb} 、 \mathrm{Cu} 、 \mathrm{Zn} 、 \mathrm{Cr} 、 \mathrm{Ni}$ 含量 均高于背景值. $0 \sim 30 \mathrm{~cm}$ 底泥内 $\mathrm{Cd}$ 含量在 $0.07 \sim 0.57 \mathrm{mg} / \mathrm{kg}$ 范围内, 平均含量为 $0.34 \mathrm{mg} / \mathrm{kg}$, 超过背景值的 $24.7 \%$; $\mathrm{Pb}$ 含量在 19.90 71.40 mg/ $\mathrm{kg}$ 范围内, 平均含量为 $36.50 \mathrm{mg} / \mathrm{kg}$, 超过背景值的 1.3 倍; $\mathrm{Cu}$ 含量在 $20.60 \sim 68.20 \mathrm{mg} / \mathrm{kg}$ 范围内, 平均含量为 $40.90 \mathrm{mg} / \mathrm{kg}$, 超过背景值的 1.1 倍; Zn 含量在 $65.40 \sim 185.00 \mathrm{mg} / \mathrm{kg}$ 范围内, 平均含量为 $123.00 \mathrm{mg} / \mathrm{kg}$, 超过背景值的 1.1 倍; Cr 含量在 $54.50 \sim 145.00 \mathrm{mg} / \mathrm{kg}$ 范围内, 平均含量 为 $95.03 \mathrm{mg} / \mathrm{kg}$, 超过背景值的 $19.8 \%$; $\mathrm{Ni}$ 含量在 $27.80 \sim 79.90 \mathrm{mg} / \mathrm{kg}$ 范围内, 平均含量为 $51.00 \mathrm{mg} / \mathrm{kg}$, 超 过背景值的 1.6 倍. (3) 贡湖主要表现为 $\mathrm{As} 、 \mathrm{~Pb} 、 \mathrm{Cu} 、 \mathrm{Zn} 、 \mathrm{Cr}$ 含量在各湖区中居第 2 位, $\mathrm{Cd} 、 \mathrm{Ni}$ 含量在各湖区中 居第 3 位, 且 $\mathrm{Cd} 、 \mathrm{As} 、 \mathrm{~Pb} 、 \mathrm{Cu} 、 \mathrm{Zn} 、 \mathrm{Cr} 、 \mathrm{Ni}$ 含量均高于背景值. $0 \sim 30 \mathrm{~cm}$ 底泥内 $\mathrm{Cd}$ 含量在 $0.10 \sim 3.60 \mathrm{mg} / \mathrm{kg}$ 范 围内, 平均含量为 $0.65 \mathrm{mg} / \mathrm{kg}$, 超过背景值的 1.4 倍; As 含量在 $4.13 \sim 41.50 \mathrm{mg} / \mathrm{kg}$ 范围内, 平均含量为 $11.73 \mathrm{mg} / \mathrm{kg}$, 超过背景值的 $24.8 \%$; Pb 含量在 $24.00 \sim 50.90 \mathrm{mg} / \mathrm{kg}$ 范围内, 平均含量为 $37.00 \mathrm{mg} / \mathrm{kg}$, 超过 背景值的 1.4 倍; $\mathrm{Cu}$ 含量在 $24.20 \sim 120.00 \mathrm{mg} / \mathrm{kg}$ 范围内, 平均含量为 $44.13 \mathrm{mg} / \mathrm{kg}$, 超过背景值的 1.3 倍; $\mathrm{Zn}$ 含量在 71.10 337.00 mg/ $\mathrm{kg}$ 范围内, 平均含量为 $138.00 \mathrm{mg} / \mathrm{kg}$, 超过背景值的 1.3 倍; Cr 含量在 58.10 $146.00 \mathrm{mg} / \mathrm{kg}$ 范围内, 平均含量为 $93.37 \mathrm{mg} / \mathrm{kg}$, 超过背景值的 $17.7 \%$; $\mathrm{Ni}$ 含量在 $27.60 \sim 70.60 \mathrm{mg} / \mathrm{kg}$ 范围 内, 平均含量为 $45.73 \mathrm{mg} / \mathrm{kg}$, 超过背景值的 1.3 倍. (4) 西部沿岸区主要表现为 $\mathrm{Cd}$ 含量在各湖区中居第 1 位, $\mathrm{Hg}$ 含量居第 2 位 (但未超过背景值), $\mathrm{Pb} 、 \mathrm{Cu} 、 \mathrm{Zn} 、 \mathrm{Ni}$ 含量居第 4 位, $\mathrm{Cr}$ 含量居第 5 位, 且 $\mathrm{Cd} 、 \mathrm{~Pb} 、 \mathrm{Cu} 、 \mathrm{Zn} 、$ $\mathrm{Ni}$ 含量均高于背景值. $0 \sim 30 \mathrm{~cm}$ 底泥内 $\mathrm{Cd}$ 含量在 $0.52 \sim 13.90 \mathrm{mg} / \mathrm{kg}$ 范围内, 平均含量为 $2.45 \mathrm{mg} / \mathrm{kg}$, 超过 背景值的 8.1 倍; $\mathrm{Pb}$ 含量在 19.00 46.00 mg/ $\mathrm{kg}$ 范围内, 平均含量为 $37.03 \mathrm{mg} / \mathrm{kg}$, 超过背景值的 1.4 倍; $\mathrm{Cu}$ 含量在 $17.20 \sim 45.60 \mathrm{mg} / \mathrm{kg}$ 范围内, 平均含量为 $32.23 \mathrm{mg} / \mathrm{kg}$, 超过背景值的 $70.5 \%$; Zn 含量在 $64.10 \sim$ $160.00 \mathrm{mg} / \mathrm{kg}$ 范围内, 平均含量为 $116.33 \mathrm{mg} / \mathrm{kg}$, 超过背景值的 $97.2 \%$; $\mathrm{Ni}$ 含量在 $17.90 \sim 58.30 \mathrm{mg} / \mathrm{kg}$ 范围 内, 平均含量为 $39.10 \mathrm{mg} / \mathrm{kg}$, 超过背景值的 1 倍. (5) 南部沿岸区主要表现为 $\mathrm{As}$ 含量在各湖区中居第 3 位, $\mathrm{Cd} 、 \mathrm{Cr}$ 含量居第 4 位, $\mathrm{Pb} 、 \mathrm{Cu} 、 \mathrm{Zn} 、 \mathrm{Ni}$ 含量居第 5 位, 且 $\mathrm{Cd} 、 \mathrm{As} 、 \mathrm{~Pb} 、 \mathrm{Cu} 、 \mathrm{Zn} 、 \mathrm{Ni}$ 含量均高于背景值. (6) 东太湖 
主要表现为 $\mathrm{As}$ 含量在各湖区中居第 5 位, 其余重金属含量均最低、居第 6 位, 且 $\mathrm{Pb} 、 \mathrm{Cu} 、 \mathrm{Zn} 、 \mathrm{Ni}$ 含量均高于 背景值, $\mathrm{Hg} 、 \mathrm{As} 、 \mathrm{Cr}$ 含量低于背景值, $\mathrm{Cd}$ 含量略高于背景值、基本持平. 从 $0 \sim 30 \mathrm{~cm}$ 不同深度区间来看, $0 \sim$ 10、10 20 cm 深度区间内不同湖区不同重金属的含量基本上均高于 $20 \sim 30 \mathrm{~cm}$ 深度区间内重金属含量, 但 贡湖的 Cd、Cu、Zn 除外; $0 \sim 10 \mathrm{~cm}$ 与 10 20 cm 深度区间之间不同湖区不同重金属的含量无明显规律, 部分 湖区部分重金属表现为 $0 \sim 10 \mathrm{~cm}$ 深度内含量高于 $10 \sim 20 \mathrm{~cm}$ 深度内含量, 也有表现为 $10 \sim 20 \mathrm{~cm}$ 深度内含量 高于 $0 \sim 10 \mathrm{~cm}$ 深度内含量, 如贡湖的 $0 \sim 10 \mathrm{~cm}$ 深度内 $\mathrm{As}$ 含量明显高于 $10 \sim 20 \mathrm{~cm}$ 深度内含量, 竺山湖的 $0 \sim$
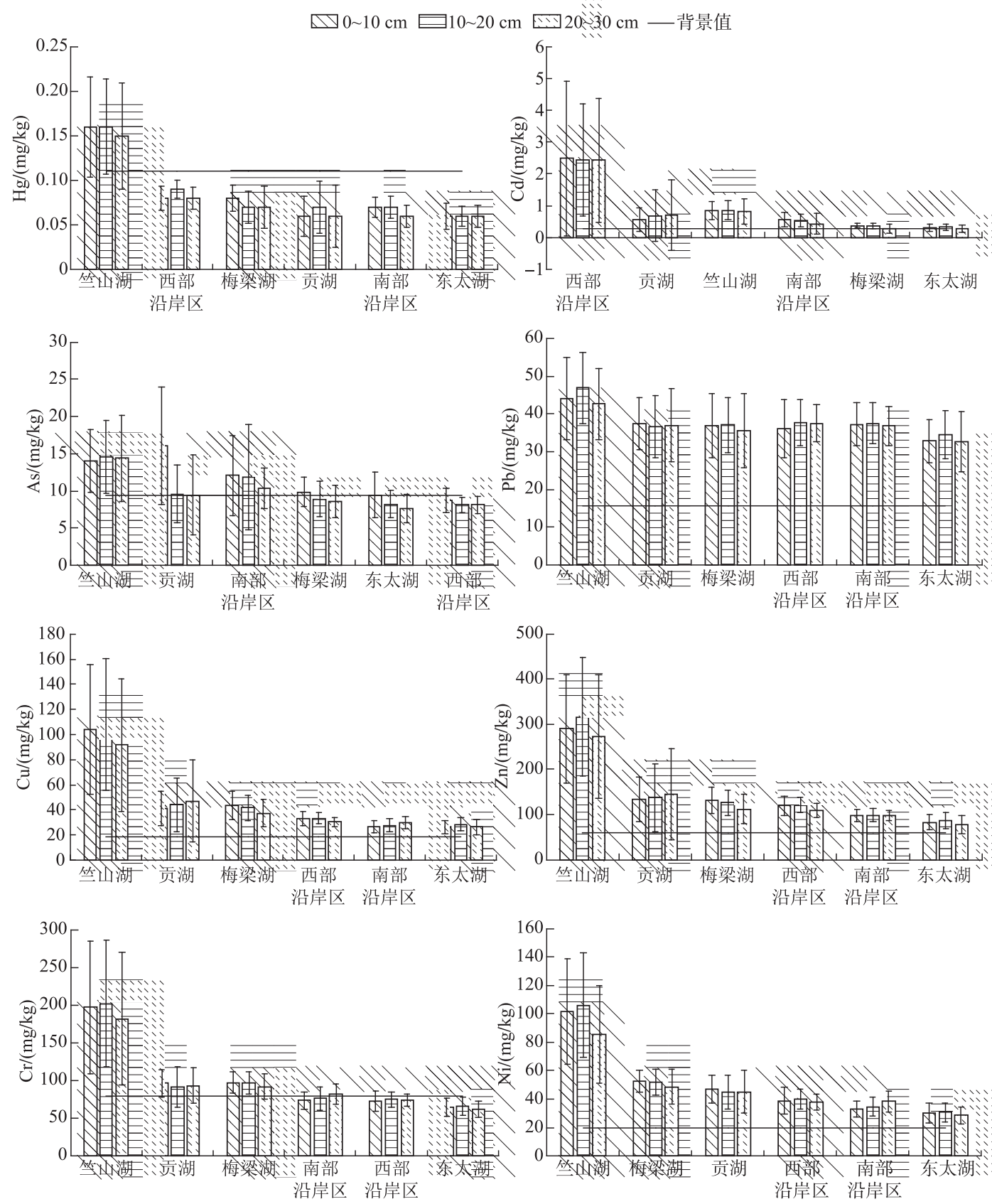

图 2 太湖沿岸区不同深度底泥重金属含量 (图中误差线以标准差计)

Fig. 2 Contents of heavy metals in sediments at different depths in the coastal area of Lake Taihu 
$10 \mathrm{~cm}$ 深度内 $\mathrm{As} 、 \mathrm{~Pb} 、 \mathrm{Cu} 、 \mathrm{Zn} 、 \mathrm{Cr} 、 \mathrm{Ni}$ 含量低于 $10 \sim 20 \mathrm{~cm}$ 深度内含量. 总体来看, 竺山湖、西部沿岸区、贡湖、 梅梁湖等湖区重金属含量较高, 南部沿岸区、东太湖重金属含量相对较低; 各个湖区的 $\mathrm{Cd} 、 \mathrm{~Pb} 、 \mathrm{Cu} 、 \mathrm{Zn} 、 \mathrm{Ni}$ 含 量, 竺山湖的 $\mathrm{Hg} 、 \mathrm{As} 、 \mathrm{Cr}$ 含量, 贡湖的 As、Cr 含量, 南部沿岸区的 As 含量和梅梁湖的 $\mathrm{Cr}$ 含量均高于背景 值; $0 \sim 30 \mathrm{~cm}$ 不同深度区间内底泥重金属含量越往表层相对越高.

\section{2 重金属潜在生态风险指数评价}

本文采用 $\mathrm{Hg} 、 \mathrm{Cd} 、 \mathrm{As} 、 \mathrm{~Pb} 、 \mathrm{Cu} 、 \mathrm{Zn} 、 \mathrm{Cr} 、 \mathrm{Ni} 8$ 种重金属计算潜在生态风险指数. 经空间插值分析 (图 3), 太 湖沿岸区 $0 \sim 30 \mathrm{~cm}$ 不同深度区间浅层底泥重金属低风险 $(R I<150)$ 的区域主要分布在东太湖、南部沿岸区、 梅梁湖绝大部分湖区、贡湖, 中风险 $(150 \leqslant R I<300)$ 的区域主要分布在竺山湖、贡湖北部、西部沿岸区北部与 南部、南部沿岸区的西北角沿岸侧, 较高风险 $(300 \leqslant R I<600)$ 的区域主要分布在西部沿岸区中部、贡湖北部、 竺山湖北部, 很高风险及以上 $(R I \geqslant 600)$ 的区域主要分布在西部沿岸区的城东港至洑西河之间近岸侧, 其中 $0 \sim 10 \mathrm{~cm}$ 深度内存在部分极高风险 $(R I \geqslant 1200)$ 的区域, $10 \sim 20 \mathrm{~cm}$ 和 $20 \sim 30 \mathrm{~cm}$ 深度内无极高风险区域. 从 不同深度区间来看, $0 \sim 10 \mathrm{~cm}$ 深度内, 低风险、中风险、较高风险、很高风险、极高风险区域面积分别为 $773.67 、 256.78 、 67.54 、 11.00 、 0.96 \mathrm{~km}^{2}$, 其中较高风险以上区域面积为 $79.50 \mathrm{~km}^{2}$, 占太湖沿岸区总面积的 $7.16 \% ; 10 \sim 20 \mathrm{~cm}$ 深度内, 低风险、中风险、较高风险、很高风险区域面积分别为 $790.39 、 224.54 、 90.83 、 4.19$ $\mathrm{km}^{2}$, 无极高风险区域, 其中较高风险以上区域面积为 $95.02 \mathrm{~km}^{2}$, 占太湖沿岸区总面积的 $8.56 \% ; 20 \sim 30 \mathrm{~cm}$ 深度内, 低风险、中风险、较高风险、很高风险区域面积分别为 $810.86 、 216.35 、 75.87 、 6.87 \mathrm{~km}^{2}$, 无极高风险区 域, 其中较高风险以上区域面积为 $82.74 \mathrm{~km}^{2}$, 占太湖沿岸区总面积的 $7.45 \%$. 综上, 西部沿岸区中部、竺山湖 北部、贡湖北部不同深度底泥内均存在重金属严重污染区域 (重金属综合潜在生态风险指数 $R I \geqslant 300$ 的区 域). 通过 GIS 叠加分析得到 $0 \sim 30 \mathrm{~cm}$ 深度区间内重金属严重污染区域主要分布在西部沿岸区中部(艾渎港 至乌溪港近岸侧),面积为 $104.54 \mathrm{~km}^{2}$, 占该湖区的 $51.33 \%$; 竺山湖北部,面积为 $10.80 \mathrm{~km}^{2}$, 占该湖区的 $16.62 \%$; 贡湖北部 (望虞河人河口附近), 面积为 $6.89 \mathrm{~km}^{2}$, 占该湖区的 $4.21 \%$; 合计面积为 $122.23 \mathrm{~km}^{2}$.
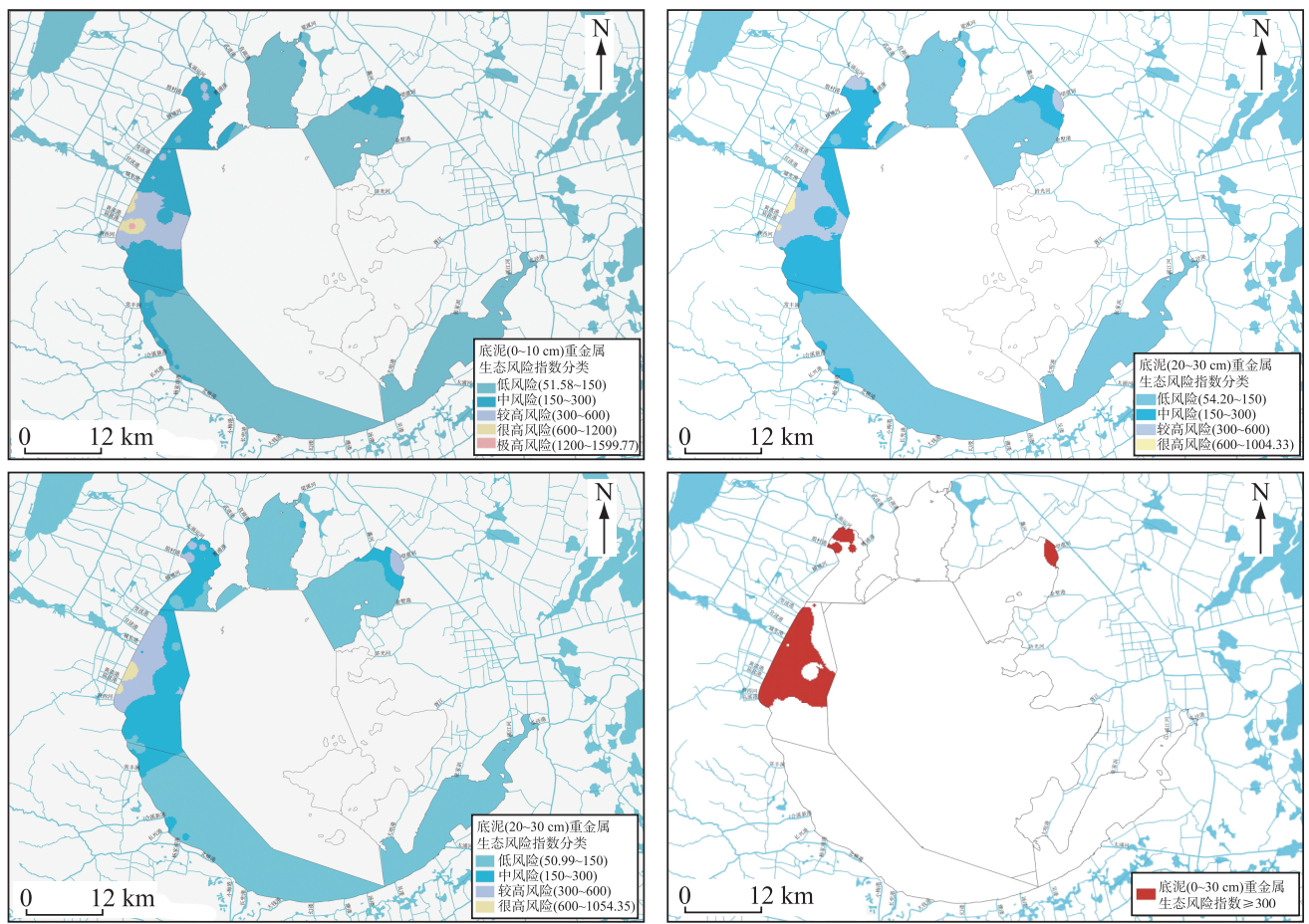

图 3 太湖沿岸区不同深度底泥重金属污染 (潜在生态风险) 分类评价

Fig.3 Evaluation diagram of heavy metal pollution (potential ecological risk) in sediments at different depths in the coastal area of Lake Taihu 
进一步分析西部沿岸区、竺山湖、贡湖 3 个湖区中重金属严重污染区域( 重金属综合潜在生态风险指数 $R I \geqslant 300$ 的区域) 中不同重金属的生态风险贡献(图 4), 发现西部沿岸区中重金属严重污染区域主要表现为 $\mathrm{Cd}$ 处于很高污染 $\left(E_{r} \geqslant 320\right), 0 \sim 30 \mathrm{~cm}$ 不同深度内 $\mathrm{Cd}$ 的 $E_{r}$ 为 $411.67 \sim 485.32$, 贡献率达 $84.15 \% \sim 86.36 \%$, 其 他重金属均处于低风险 $\left(E_{r}<40\right)$; 竺山湖中重金属严重污染区域表现为 $\mathrm{Cd} 、 \mathrm{Hg}$ 处于较高风险 $\left(80 \leqslant E_{r}<\right.$ $160), 0 \sim 30 \mathrm{~cm}$ 不同深度内 $\mathrm{Cd}$ 的 $E_{r}$ 为 $107.22 \sim 127.50$, 贡献率为 $32.47 \% \sim 38.75 \%, \mathrm{Hg}$ 的 $E_{r}$ 为 $80.00 \sim 85.94$, 贡献率为 $24.22 \% \sim 25.05 \%$; 贡湖中重金属严重污染区域表现为 Cd 处于很高污染 $\left(E_{r} \geqslant 320\right), 0 \sim 30 \mathrm{~cm}$ 不同 深度内 $\mathrm{Cd}$ 的 $E_{r}$ 为 $201.11 \sim 400.00$, 贡献率为 $64.34 \% \sim 77.37 \%$. 因此, 西部沿岸区、贡湖主要表现为 Cd 污染, 竺山湖主要表现为 $\mathrm{Cd} 、 \mathrm{Hg}$ 复合污染, 且西部沿岸区的 $\mathrm{Cd}$ 污染最为严重.

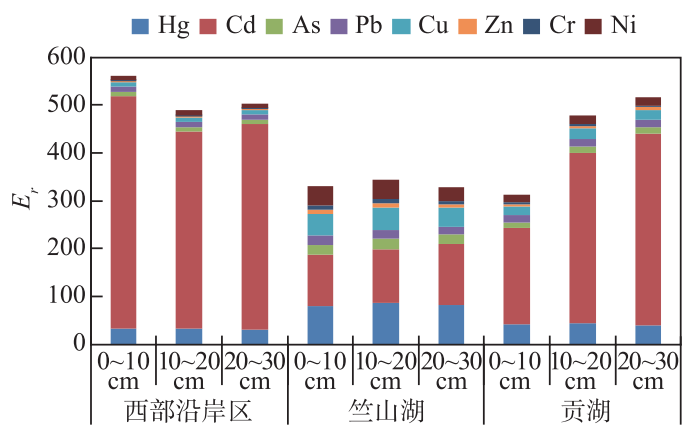

重金属生态风险指数 $R I \geqslant 300$ 的区域

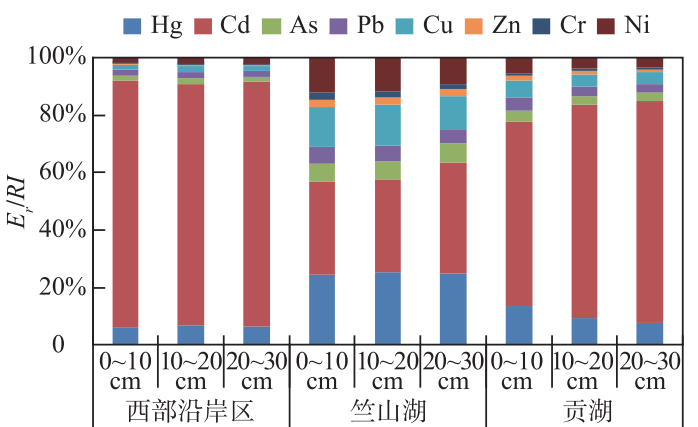

重金属生态风险指数 $R I \geqslant 300$ 的区域

图 4 太湖沿岸区重金属严重污染区域 $(R I \geqslant 300)$ 中不同重金属潜在生态风险指数情况

Fig.4 Potential ecological risk index of different heavy metals in the seriously polluted area of heavy metals $(R I \geqslant 300)$ in the coastal area of Lake Taihu

\section{表 3 太湖沿岸区浅层底泥重金属主成分分析}

Tab.3 Principal component analysis of heavy metals in shallow sediments in the coastal area of Lake Taihu

\begin{tabular}{ccc}
\hline \multirow{2}{*}{ 重金属元素 } & \multicolumn{2}{c}{ 主成分载荷 } \\
\cline { 2 - 3 } & $F_{1}$ & $F_{2}$ \\
\hline $\mathrm{Hg}$ & 0.890 & 0.241 \\
$\mathrm{Cd}$ & 0.057 & 0.910 \\
$\mathrm{As}$ & 0.555 & -0.432 \\
$\mathrm{~Pb}$ & 0.717 & -0.125 \\
$\mathrm{Cu}$ & 0.964 & 0.041 \\
$\mathrm{Zn}$ & 0.977 & 0.096 \\
$\mathrm{Cr}$ & 0.964 & -0.060 \\
$\mathrm{Ni}$ & 0.960 & -0.013 \\
特征值 & 5.356 & 1.103 \\
贡献率/\% & 66.95 & 13.79 \\
累积贡献率/\% & 66.95 & 80.74 \\
\hline
\end{tabular}

\section{3 重金属来源探讨分析}

主成分分析 (表 3、图 5) 表明,太湖沿岸区浅层 底泥中 8 种重金属所代表的全部信息可以由 $F_{1}$ 和 $F_{2} 2$ 个主成分表达, 其特征值分别为 5.356、1.103, 累积贡献率为 $80.74 \%$, 通过对这两个主成分的分析 基本上能够反映数据所代表的大部分信息. 第一主 成分的贡献率为 $66.95 \%$, 其中 $\mathrm{Zn} 、 \mathrm{Cu} 、 \mathrm{Cr} 、 \mathrm{Ni} 、 \mathrm{Hg}$ 表 现出较高的载荷 $(>0.8)$, Pearson 相关分析 (表 4) 表 明 $\mathrm{Zn} 、 \mathrm{Cu} 、 \mathrm{Cr} 、 \mathrm{Ni} 、 \mathrm{Hg}$ 之间相关性显著, 具有相似的 来源, $\mathrm{Zn} 、 \mathrm{Cu} 、 \mathrm{Cr} 、 \mathrm{Ni}$ 主要来源于电镀、机械制造、金 属冶炼、皮革生产等工业产业 ${ }^{[14,39]}, \mathrm{Hg}$ 主要来源于 电镀、化工、造纸、医院等行业排放的废水以及含 $\mathrm{Hg}$ 农药 ${ }^{[40]}$,所以第一主成分主要代表着工业废水对浅 层底泥的重金属污染. 此外, $\mathrm{Pb} 、 \mathrm{As}$ 在第一个主成分 上也表现出中等载荷 (分别为 $0.717 、 0.555$ ), 且与 $\mathrm{Cu} 、 \mathrm{Zn} 、 \mathrm{Cr} 、 \mathrm{Ni}$ 相关性显著, 可知第一主成分也部分 支配着 $\mathrm{Pb} 、 \mathrm{As}$ 的来源, $\mathrm{Pb}$ 除了来自电镀等工业废水

外, 合成橡胶和 PVC 工厂在生产过程中会使用含 $\mathrm{Pb}$ 的添加剂, 河湖行船含 $\mathrm{Pb}$ 汽油的使用引起的大气沉降 也是 $\mathrm{Pb}$ 的来源 ${ }^{[14,30,39-40]}$, As 主要来源于医药、化肥、纺织、印染等行业排放的废水以及燃煤 ${ }^{[14,40]}$. 第二主成 分的贡献率为 $13.79 \%, \mathrm{Cd}$ 表现为较高的载荷 (0.910), 而其在第一主成分载荷较低 ( 0.057$)$, 且 Cd 与其他重 金属的相关性均不显著或很低, 说明 $\mathrm{Cd}$ 的污染源与其他元素不同, $\mathrm{Cd}$ 主要来自于传统农业生产中长期使 用农药和化肥 ${ }^{[14,39]}$, 因此第二主成分主要表征了农业面源对浅层底泥中 Cd 含量的影响. 


\section{4 重金属含量及生态风险评价已有成果对比分析}

进一步基于已有文献成果,分析太湖不同湖区浅层底 泥的重金属含量变化情况 (表 5) 以及潜在生态风险指数变 化状况 (表 6). 分析发现,较 2007 年各湖区重金属含 量 ${ }^{[27]}$,梅梁湖的 $\mathrm{Hg} 、 \mathrm{Cd} 、 \mathrm{As} 、 \mathrm{~Pb} 、 \mathrm{Cu}$ 含量有所减少, $\mathrm{Cr}$ 含量 有所增加; 较 2007 年,竺山湖的 $\mathrm{Hg}$ 含量保持不变, $\mathrm{Pb}$ 含量 略有增加, $\mathrm{Cd} 、 \mathrm{Cu} 、 \mathrm{Cr}$ 含量有所增加且增幅较大, As 含量有 所减少,较 2014 年,竺山湖的 $\mathrm{Cd} 、 \mathrm{As} 、 \mathrm{~Pb} 、 \mathrm{Cu} 、 \mathrm{Zn}$ 含量有所 减少, $\mathrm{Cr}$ 含量有所增加, $\mathrm{Ni}$ 含量基本保持不变; 较 2007 年, 贡湖的 $\mathrm{Hg} 、 \mathrm{Cd} 、 \mathrm{As} 、 \mathrm{~Pb} 、 \mathrm{Cu} 、 \mathrm{Cr}$ 含量均有所减少, 东太湖的 $\mathrm{Hg} 、 \mathrm{As} 、 \mathrm{Cr}$ 含量有所增加、 $\mathrm{Cd} 、 \mathrm{~Pb} 、 \mathrm{Cu}$ 含量有所减少, 西部与 南部沿岸区的 $\mathrm{Hg} 、 \mathrm{Cd} 、 \mathrm{Cu} 、 \mathrm{Cr}$ 含量有所增加、 $\mathrm{As} 、 \mathrm{~Pb}$ 含量有 所减少. 由于不同学者的采样时间、采样点数量、计算重金 属生态风险时关注的重金属元素、采用的背景值不一样等 诸多原因,不同研究得出的太湖重金属综合潜在生态风险 指数 $(R I)$ 不宜直接开展对比分析, 但是从总体规律上来

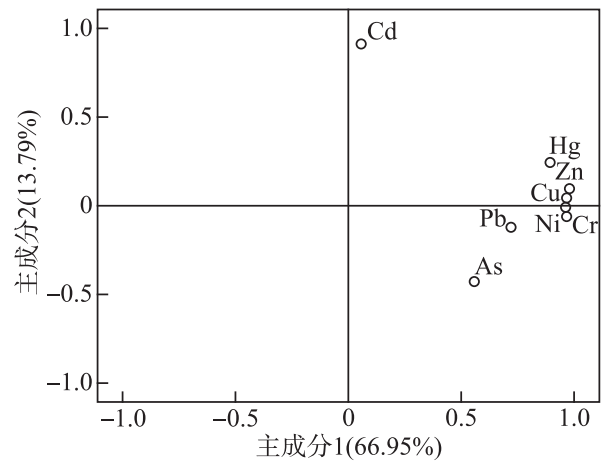

图 5 太湖沿岸区浅层底泥重金属主成分 1 和 2 解释重金属的载荷

Fig. 5 Loads of the explanation of principal components 1 and 2 of heavy metals in shallow sediments in the coastal area of Lake Taihu

表 4 太湖沿岸区浅层底泥重金属元素之间的 Pearson 相关系数

Tab.4 Pearson correlation coefficients of the heavy metal elements in shallow sediments in the coastal area of Lake Taihu

\begin{tabular}{ccccccccc}
\hline 重金属 & $\mathrm{Hg}$ & $\mathrm{Cd}$ & $\mathrm{As}$ & $\mathrm{Pb}$ & $\mathrm{Cu}$ & $\mathrm{Zn}$ & $\mathrm{Cr}$ & $\mathrm{Ni}$ \\
\hline $\mathrm{Hg}$ & 1 & $0.186^{* *}$ & $0.313^{* *}$ & $0.569^{* *}$ & $0.865^{* *}$ & $0.892^{* *}$ & $0.809^{* *}$ & $0.833^{* * *}$ \\
$\mathrm{Cd}$ & & 1 & $-0.092^{*}$ & 0.031 & 0.039 & $0.106^{*}$ & $-0.028^{* *}$ & $-0.002^{*}$ \\
$\mathrm{As}$ & & & 1 & $0.498^{* *}$ & $0.447^{* *}$ & $0.452^{* *}$ & $0.506^{* *}$ & $0.444^{* *}$ \\
$\mathrm{~Pb}$ & & & & 1 & $0.564^{* *}$ & $0.610^{* *}$ & $0.601^{* *}$ & $0.642^{* *}$ \\
$\mathrm{Cu}$ & & & & & 1 & $0.977^{* *}$ & $0.962^{* *}$ & $0.931^{* *}$ \\
$\mathrm{Zn}$ & & & & & & $0.953^{* *}$ & $0.945^{* *}$ \\
$\mathrm{Cr}$ & & & & & & 1 & $0.948^{* *}$ \\
$\mathrm{Ni}$ & & & & & & & 1 \\
\hline
\end{tabular}

** 表示在 0.01 级别 (双尾) 相关性显著; * 表示在 0.05 级别 (双尾) 相关性显著.

表 5 不同年份太湖不同湖区浅层底泥重金属含量 $(\mathrm{mg} / \mathrm{kg}) *$

Tab.5 Contents of heavy metals in shallow sediments in different parts of Lake Taihu in different years

\begin{tabular}{|c|c|c|c|c|c|c|c|c|c|c|}
\hline 湖区 & 文献 & 采样时间 & $\mathrm{Hg}$ & $\mathrm{Cd}$ & As & $\mathrm{Pb}$ & $\mathrm{Cu}$ & $\mathrm{Zn}$ & $\mathrm{Cr}$ & $\mathrm{Ni}$ \\
\hline \multirow[t]{2}{*}{ 梅梁湖 } & 尹洪斌等[27] & 2007 年 & 0.12 & 0.66 & 12.50 & 44.00 & 49.10 & / & 70.60 & / \\
\hline & 本文 & 2018 年 & 0.07 & 0.34 & 9.12 & 36.50 & 40.90 & 123.00 & 95.03 & 51.00 \\
\hline \multirow[t]{3}{*}{ 竺山湖 } & 尹洪斌等[27] & 2007 年 & 0.16 & 0.49 & 21.90 & 44.30 & 49.70 & / & 77.50 & / \\
\hline & 周亚子等 [14] & 2014 年 & / & 1.15 & 19.44 & 48.50 & 134.15 & 383.76 & 179.95 & 97.15 \\
\hline & 本文 & 2018 年 & 0.16 & 0.84 & 14.33 & 44.53 & 101.23 & 293.00 & 193.67 & 97.70 \\
\hline \multirow[t]{2}{*}{ 贡湖 } & 尹洪斌等 [27] & 2007 年 & 0.33 & 0.85 & 15.20 & 57.10 & 53.20 & 1 & 95.60 & / \\
\hline & 本文 & 2018 年 & 0.06 & 0.65 & 11.73 & 37.00 & 44.13 & 138.00 & 93.37 & 45.73 \\
\hline \multirow[t]{2}{*}{ 东太湖 } & 尹洪斌等[27] & 2007 年 & 0.03 & 0.97 & 7.13 & 54.00 & 31.30 & I & 53.40 & / \\
\hline & 本文 & 2018 年 & 0.06 & 0.30 & 8.45 & 33.30 & 27.17 & 82.33 & 64.20 & 29.77 \\
\hline 西部、南部 & 尹洪斌等 [27] & 2007 年 & 0.05 & 1.28 & 12.70 & 48.90 & 28.40 & / & 44.70 & 1 \\
\hline 沿岸区平均 & 本文 & 2018 年 & 0.08 & 1.48 & 9.90 & 37.10 & 30.10 & 107.05 & 75.35 & 37.20 \\
\hline
\end{tabular}

* 尹洪斌等 ${ }^{[27]}$ 的采样时间为 2007 年 8-9 月,在太湖全湖布设采样点 206 个; 周亚子等 ${ }^{[14]}$ 的采样时间为 2014 年 4 月, 在竺山湖布设采样点 4 个. / 表示对应文献没有测定该重金属含量. 
表 6 太湖浅层底泥重金属生态风险指数历史数据对比 *

Tab.6 Comparison of historical datas of heavy metal ecological risk index in shallow sediments in Lake Taihu

\begin{tabular}{|c|c|c|c|c|c|c|c|c|c|c|c|}
\hline \multirow{2}{*}{ 文献 } & \multirow{2}{*}{ 采样时间 } & \multirow{2}{*}{$\begin{array}{c}\text { 采样点 } \\
\text { 数量 }\end{array}$} & \multicolumn{8}{|c|}{$E_{r}$} & \multirow{2}{*}{$R I$} \\
\hline & & & $\mathrm{Hg}$ & $\mathrm{Cd}$ & As & $\mathrm{Pb}$ & $\mathrm{Cu}$ & $\mathrm{Zn}$ & $\mathrm{Cr}$ & $\mathrm{Ni}$ & \\
\hline 向勇等[24] & 2002 年 3 月 & 20 & 15.56 & 9.74 & 6.97 & 7.24 & 5.49 & 1.23 & 1.20 & / & 47.43 \\
\hline 尹洪斌等 ${ }^{[27]}$ & 2007 年 $8-9$ 月 & 206 & 41.4 & 104 & 14.3 & 16.5 & 9.71 & / & 1.42 & / & 187.33 \\
\hline 秦延文等[30] & 2011 年 8-9月 & 30 & / & 26.87 & / & 7.65 & 3.71 & 0.72 & / & 1 & 38.95 \\
\hline 刘莹等[19] & 2012 年 2 月 & 7 & / & / & / & 10.06 & 8.57 & 1.59 & 2.22 & 10.16 & 32.60 \\
\hline 任杰等[17] & 2015 年 10 月 & 21 & / & 134.23 & / & 8.16 & 7.52 & 1.86 & 2.28 & 7.36 & 161.41 \\
\hline 邓延慧等 ${ }^{[20]}$ & 2020 年 3 月 & 20 & 12.52 & 16.85 & 9.01 & 6.52 & 7.02 & 1.63 & 2.41 & / & 55.04 \\
\hline 本文 & 2018 年 $10-11$ 月 & 230 & 28.79 & 90.90 & 11.13 & 11.90 & 10.63 & 2.17 & 2.32 & 11.80 & 169.64 \\
\hline
\end{tabular}

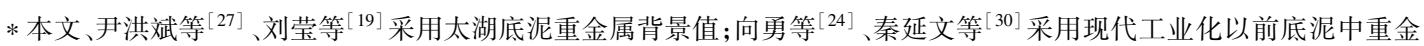
属最高背景值; 任杰等 ${ }^{[17]}$ 采用江苏省土壤重金属背景值; 邓延慧等 ${ }^{[20]}$ 采用 1980 年太湖沿岸土壤中重金属的自然本底 值. / 表示对应文献没有测定该重金属含量.

看, 2000 年以来,相较于其他元素, $\mathrm{Cd}$ 元素的生态风险最为严重, $\mathrm{Hg}$ 元素的生态风险次之; 较 2007 年各重金 属的潜在生态风险指数 ${ }^{[27]}, \mathrm{Hg} 、 \mathrm{Cd} 、 \mathrm{As} 、 \mathrm{~Pb}$ 的潜在生态风险指数有所下降, $\mathrm{Cu} 、 \mathrm{Cr}$ 的潜在生态风险指数略有 增加. 出现这种现象, 除了与不同学者的采样条件、采样环境、样品数量、浅层底泥的深度等不同有关之外, 也可能与不同年份的水雨情、人湖污染变化情况、蓝藻暴发情况 ${ }^{[4-42]}$ 、不同湖区开展的局部底泥疏浚情 况 ${ }^{[3,43]}$ 、不同湖区沉积物沉积速率不同 ${ }^{[44]}$ 等诸多因素有关, 这也说明了太湖浅层底泥重金属分布的复杂性, 不同湖区不同重金属元素的空间分布差异性较大.

\section{3 结论}

1) 太湖沿岸区浅层底泥中重金属分布具有明显的空间异质性,竺山湖、西部沿岸区、贡湖、梅梁湖等湖 区重金属含量较高, 南部沿岸区、东太湖重金属含量相对较低; 各个湖区的 $\mathrm{Cd} 、 \mathrm{~Pb} 、 \mathrm{Cu} 、 \mathrm{Zn} 、 \mathrm{Ni}$ 含量, 竺山湖的 $\mathrm{Hg} 、 \mathrm{As} 、 \mathrm{Cr}$ 含量, 贡湖的 As、Cr 含量, 南部沿岸区的 As 含量和梅梁湖的 Cr 含量均高于背景值.

2) 潜在生态风险指数法评价结果显示, 太湖沿岸区浅层底泥中重金属严重污染区域 (重金属综合潜在 生态风险指数 $R I \geqslant 300$ 的区域) 主要分布在西部沿岸区中部 (荠渎港至乌溪港近岸侧)、竺山湖北部、贡湖北 部 (望虞河人河口附近), 面积分别约为 $104.54 、 10.80 、 6.89 \mathrm{~km}^{2} ; \mathrm{Cd}$ 和 $\mathrm{Hg}$ 是主要的重金属生态风险贡献因 子、且毒性较强, 西部沿岸区、贡湖主要表现为 $\mathrm{Cd}$ 处于很高污染程度, 竺山湖主要表现为 $\mathrm{Cd} 、 \mathrm{Hg}$ 处于较高风 险程度.

3) 重金属源分析结果表明, 太湖沿岸区浅层底泥中 $\mathrm{Zn} 、 \mathrm{Cu} 、 \mathrm{Cr} 、 \mathrm{Ni} 、 \mathrm{Hg} 、 \mathrm{~Pb} 、 \mathrm{As}$ 具有相似的来源, 可能主要 来自于工业污染; $\mathrm{Cd}$ 可能主要来自于农业污染.

4) 太湖浅层底泥重金属分布及变化过程较为复杂, 建议持续开展底泥重金属污染监测与评价工作; 对 于重金属生态风险较高的区域, 特别是西部沿岸区, 建议加强 $\mathrm{Cd}$ 的污染防控, 在控制好外源污染的前提下 可开展局部生态清淤试点; 建议在今后的工作中, 开展太湖底泥沉积物一水界面重金属迁移转化、底泥重金 属释放机理、底泥重金属与太湖水环境质量之间的关系等研究.

致谢: 感谢水利部太湖流域管理局提供的太湖水下地形测量及污染底泥勘察项目中关于太湖沿岸区浅层底 泥重金属的监测化验数据, 感谢中水北方勘测设计研究有限责任公司和广东地质实验测试中心在现场采样 与监测化验等过程中付出的辛劳.

\section{4 参考文献}

[ 1 ] Yang LY, Shen J, Zhang ZL et al. Distribution and ecological risk assessment for heavy metals in superficial sediments of Nansihu Lake. J Lake Sci, 2003, 15(3) : 252-256. DOI: 10.18307/2003.0309. [杨丽原, 沈吉, 张祖陆等. 南四湖表 层底泥重金属污染及其风险性评价. 湖泊科学, 2003, 15(3) : 252-256.] 
[ 2 ] Ren XL, Zhu L, Yao H et al. Distribution of heavy metals in sediments of Zhushan Lake and northern segment of western shore of Taihu Lake and its ecological risk assessment. Water Resources Protection, 2012, 28(5): 43-47. [ 任小龙, 朱玲, 姚华等. 竺山湖及太湖西沿岸北段的重金属分布特征及其生态风险评价. 水资源保护，2012，28(5): 43-47.]

[ 3 ] Mao ZG, Gu XH, Lu XM et al. Pollution distribution and potential ecological risk assessment of heavy metals in sediments from the different eastern dredging regions of Lake Taihu. Environmental Science, 2014, 35(1): 186-193. DOI: 10. 13227/j.hjkx.2014.01.027. [毛志刚, 谷孝鸿, 陆小明等. 太湖东部不同类型湖区疏浚后沉积物重金属污染及潜在 生态风险评价. 环境科学, 2014, 35(1): 186-193.]

[ 4 ] Bing HJ, Wu YH, Liu EF et al. The accumulation and potential ecological risk evaluation of heavy metals in the sediment of different lakes within the middle and lower reaches of Yangtze River. J Lake Sci, 2010, 22 (5) : 675-683. DOI: 10. 18307/2010.0508. [邴海健, 吴艳宏, 刘恩峰等. 长江中下游不同湖泊沉积物中重金属污染物的累积及其潜在生态 风险评价. 湖泊科学, 2010, 22(5):675-683.]

[ 5 ] Yuan HZ, Shen J, Liu EF. Assessment and characterization of heavy metals and nutrients in sediments from Taihu Lake. Environmental Science, 2011, 32(3) : 649-657. DOI: 10.13227/j.hjkx.2011.03.006. [袁和忠, 沈吉, 刘恩峰. 太湖重 金属和营养盐污染特征分析. 环境科学, 2011, 32(3):649-657.]

[ 6 ] Fan CX, Liu M, Wang SR et al. Research progress and prospect of sediment environment and pollution control in China in recent 20 years. Advances in Earth Science, 2021, 36(4) : 346-374. [范成新, 刘敏, 王圣瑞等. 近 20 年来我国沉积物 环境与污染控制研究进展与展望. 地球科学进展, 2021, 36(4) : 346-374.]

[ 7 ] Tang C, Qian B, Li WQ et al. Pollution characteristics and risk evaluation of heavy metals in surface sediments of Dongting Lake. Yangtze River, 2020, 51(6): 49-56,62. [唐聪, 钱宝, 李炜钦等. 洞庭湖区表层沉积物重金属污染特征与风 险评价. 人民长江, $2020, \mathbf{5 1}(6): 49-56,62$.]

[ 8 ] Liu X, Jiang Y, Gao JF et al. Pollution characteristics of heavy metals and the risk assessment for the surface sediments from Lake Chaohu and its main tributary rivers. J Lake Sci, 2016, 28(3) : 502-512. DOI: 10.18307/2016.0305. [刘新, 蒋豫, 高俊峰等. 巢湖湖区及主要出人湖河流表层沉积物重金属污染特征及风险评价. 湖泊科学, 2016, 28(3): 502-512.]

[ 9 ] Sun ZB, Bing HJ, Wu YH et al. Contamination and potential ecological risk of heavy metals in lacustrine sediment core from Lake Xijiu, Taihu Basin. J Lake Sci, 2009, 21(4) : 563-569. DOI: 10.18307/2009.0416. [孙照斌, 邴海健, 吴 艳宏等. 太湖流域西氿湖沉积岩芯中重金属污染及潜在生态风险. 湖泊科学, 2009, 21(4) : 563-569.]

[10] Chen W, Liu W, Sun W. The integrated development of Taihu Basin and the Yangtze River Delta region: Status, challenges and strategies. J Lake Sci, 2021, 33(2) : 327-335. DOI: 10.18307/2021.0201. [陈雯, 刘伟, 孙伟. 太湖与长三角 区域一体化发展: 地位、挑战与对策. 湖泊科学, 2021, 33(2): 327-335.]

[11] Yan XC, Yang XW, Huang XQ et al. Distribution and risk assessment of heavy metals in the surface estuarine sediments of main inflow rivers in Taihu Lake. Ecology and Environmental Sciences, 2016, 25(9): 1515-1521. [间兴成, 杨晓薇, 黄 烯茜等. 太湖主要人湖河口表层沉积物重金属分布特征及风险评价. 生态环境学报, 2016, 25(9): 1515-1521.]

[12] Huang SS, Fan DF, Chen B et al. A temporal assessment on ecological risk caused by heavy metals in north Taihu basin. Jiangsu Geology, 2005, 29(1)：43-45. [ 黄顺生, 范迪富, 陈宝等. 太湖北部沉积物重金属污染及其潜在生态危害 评价. 江苏地质, 2005, 29(1): 43-45.]

[13] Meng C, Hou YH, Zheng L. Risk assessment of nitrogen, phosphorus and heavy metals in surface sediment of Meiliang Bay estuarine, Taihu Lake. Journal of Shandong Agricultural University: Natural Science Edition, 2019, 50(2) : 297-303. [孟翠, 侯艳红, 郑否. 太湖梅梁湾湖口表层沉积物中氮磷、重金属的风险评价. 山东农业大学学报: 自然科学版, 2019, 50(2) : 297-303.]

[14] Zhou YZ, Chen X, Liu S et al. Pollution of heavy metals in surface sediments of Zhushan Bay and its main inflow rivers and assessment of their potential ecological risks. Environmental Chemistry, 2016, 35(8): 1557-1566. [周亚子, 陈䂀, 刘莎等. 太湖竺山湾及其主要人湾河流表层沉积物重金属污染及潜在生态风险评估. 环境化学, 2016, 35(8): 1557-1566. ]

[15] Zhu GW, Qin BQ, Gao G et al. Accumulation characteristics of heavy metals in the sediments of Lake Taihu, China. $J$ Lake Sci, 2005, 17(2) : 143-150. DOI: 10.18307/2005.0209. [ 朱广伟, 秦伯强, 高光等. 太湖近代沉积物中重金属 元素的累积. 湖泊科学, 2005, 17(2): 143-150.]

[16] Qu WC, Dickman M, Wang SM. Multivariate analysis of heavy metal and nutrient concentrations in sediments of Taihu 
Lake, China. Hydrobiologia, 2001, 450(1/2/3) : 83-89. DOI: 10.1023/A: 1017551701587.

[17] Ren J, Bai L, Li J et al. Pollution evaluation and source apportionment of heavy metals in surface sediments of the Taihu Lake. Earth and Environment, 2021, 49(4): 416-427. [任杰, 白莉, 李军等. 太湖表层沉积物重金属污染评价与来 源分析. 地球与环境, 2021, 49(4): 416-427.]

[18] Zhang Y, Hu XN, Yu T. Distribution and risk assessment of metals in sediments from Taihu Lake, China using multivariate statistics and multiple tools. Bulletin of Environmental Contamination and Toxicology, 2012, 89(5) : 1009-1015. DOI: 10.1007/s00128-012-0784-7.

[19] Liu Y, Xiao L. Comprehensive evaluation of ecological risk of heavy metal pollution in the surface sediments of Taihu Lake. Environmental Protection Science, 2014, 40(3): 46-50,96. [刘荣, 肖琳. 太湖沉积物重金属污染生态风险的综合评 价. 环境保护科学, 2014, 40(3) : 46-50,96.]

[20] Deng YH, Wang ZW, Ding RN et al. Study on pollution characteristics of nutrient salts and heavy metals in sediment of Taihu Lake. Environmental Ecology, 2020,2(12): 67-72. 邓邓延慧, 王正文, 丁润楠等. 太湖湖体沉积物营养盐和重 金属污染特征研究. 环境生态学, 2020, 2(12): 67-72.]

[21] Niu Y, Jiang X, Wang K et al. Meta analysis of heavy metal pollution and sources in surface sediments of Lake Taihu, China. Science of the Total Environment, 2020, 700: 134509. DOI: 10.1016/j. scitotenv.2019.134509.

[22] Wang H, Wang CX, Wang ZJ. Speciations of heavy metals in surface sediment of Taihu Lake. Environmental Chemistry, 2002, 21 (5): 430-435. [王海, 王春霞, 王子健. 太湖表层沉积物中重金属的形态分析. 环境化学, 2002, 21(5): 430-435.]

[23] Yuan XY, Chen J, Lv BY et al. Characteristics and variation of trace elements in sediments from Taihu Lake: Effects of natural processes and human activities. Geological Review, 2003, 49(5) : 552-560. DOI: 10.16509/j.georeview.2003.05. 015. [袁旭音, 陈骏, 吕宝源等. 太湖沉积物微量元素特征和变化: 自然与人类活动的影响. 地质论评, 2003,49 ( 5 ) : 552-560.]

[24] Xiang Y, Miao QL, Feng JF. Pollution of heavy metals in the bottom mud of Lake Taihu and its assessment of potential ecological risk. Journal of Nanjing Institute of Meteorology, 2006, 29(5): 700-705. [ 向勇, 缪启龙, 丰江帆. 太湖底泥中 重金属污染及潜在生态危害评价. 南京气象学院学报, 2006, 29(5): 700-705.]

[25] Department of Environmental Protection, Shanghai Normal University, Wuxi Environmental Protection Bureau of Jiangsu eds. Study on environmental quality in Lake Taihu. Journal of Shanghai Teachers College, Special Issue on Environmental Protection, 1983. [上海师院环境保护研究室, 江苏省无锡市环境保护局. 太湖环境质量调查研究. 上海师范学院 学报, 自然科学版环境保护专辑, 1983.]

[26] Sun SC, Huang YP eds. Taihu Lake. Beijing: Ocean Press, 1993: 219-244. [孙顺才, 黄渏平. 太湖. 北京: 海洋出版 社, 1993: 219-244.]

[27] Yin HB, Gao YN, Fan CX. Distribution, sources and ecological risk assessment of heavy metals in surface sediments from Lake Taihu, China. Environmental Research Letters, 2011, 6(4) : 044012. DOI: 10.1088/1748-9326/6/4/044012.

[28] Chen CX, Jiang X, Zhan YZ et al. Speciation distribution and potential ecological risk assessment of heavy metals in sediments of Taihu Lake. China Environmental Science, 2011, 31(11)：1842-1848. [陈春霄, 姜霞, 战玉柱等. 太湖表层 沉积物中重金属形态分布及其潜在生态风险分析. 中国环境科学, 2011, 31(11)：1842-1848.]

[29] Liu EF, Birch GF, Shen J et al. Comprehensive evaluation of heavy metal contamination in surface and core sediments of Taihu Lake, the third largest freshwater lake in China. Environmental Earth Sciences, 2012, 67(1) : 39-51. DOI: 10. 1007/s12665-011-1478-x.

[30] Qin YW, Zhang L, Zheng BH et al. Speciation and pollution characteristics of heavy metals in the sediment of Taihu Lake. Environmental Science, 2012, 33(12): 4291-4299. DOI: 10.13227/j.hjkx.2012.12.037. [秦延文, 张雷, 郑丙辉等. 太 湖表层沉积物重金属赋存形态分析及污染特征. 环境科学, 2012, 33(12): 4291-4299.]

[31] Niu Y, Jiao W, Yu H et al. Spatial evaluation of heavy metals concentrations in the surface sediment of Taihu Lake. International Journal of Environmental Research and Public Health, 2015, 12 (12): 15028-15039. DOI: 10.3390/ijerph121214966.

[32] Cai YJ, Zhang EL, Liu EF et al. Spatio-temporal characteristics of heavy metal pollution and potential ecological risk in the sediments of Lake Yangzonghai, Yunnan Province. J Lake Sci, 2017, 29( 5) : 1121-1133. DOI: 10.18307/2017.0510. [蔡艳洁, 张恩楼, 刘恩峰等. 云南阳宗海沉积物重金属污染时空特征及潜在生态风险. 湖泊科学, 2017, 29(5): 
1121-1133.]

[33] Yi YJ, Wang WJ, Song J. Pollution characteristics, potential ecological risk assessment and source analysis of heavy metals of sediment in the middle and lower reaches of the Yangtze River. Water Resources and Hydropower Engineering, 2019, 50 (2) : 1-7. [ 易雨君, 王文君, 宋款. 长江中下游底泥重金属污染特征、潜在生态风险评价及来源分析. 水利水电技 术, $2019, \mathbf{5 0}(2): 1-7$.

[34] Yu JJ, Yin HB, Gao YN et al. Characteristics of nutrient and heavy metals pollution in sediments of Taihu watershed. China Environmental Science, 2017, 37(6): 2287-2294. [于佳佳, 尹洪斌, 高永年等. 太湖流域沉积物营养盐和重金属 污染特征研究. 中国环境科学, 2017, 37(6): 2287-2294.]

[35] Tao DJ, Ji XF, Ma QZ. Research on the background of heavy metals along bank of the lake. Journal of Shanghai Teachers College, Special Issue on Environmental Protection, 1983: 95-111.

[36] Li ZQ, Fang P, Huang B et al. Distribution and ecological risk assessment of nitrogen, phosphorus and heavy metals in surface sediments of typical internal lakes in Dongting Lake Area. Research of Environmental Sciences, 2020, 33(6): 1409-1420. [ 李照全, 方平, 黄博等. 洞庭湖区典型内湖表层沉积物中氮、磷和重金属空间分布与污染风险评价. 环境科学研究, 2020, 33(6): 1409-1420.]

[37] Kuang HF, Hu CH, Wu GL et al. Combination of PCA and PMF to apportion the sources of heavy metals in surface sediments from Lake Poyang during the wet season. J Lake Sci, 2020, 32(4) : 964-976. DOI: 10.18307/2020.0406. [匡荟 芬, 胡春华, 吴根林等. 结合主成分分析法 (PCA) 和正定矩阵因子分解法 (PMF) 的鄱阳湖丰水期表层沉积物重金 属源解析. 湖泊科学, 2020, 32(4): 964-976.]

[38 ] Han ZR, Zhao ZZ, Yuan JP et al. Analysis of correlation features of heavy metal elements distribution and its pollution sources in surface sediments from the Mangrove Wetlands of Northern Hainan Island. Journal of Hainan Normal University: Natural Science, 2013, 26(1): 66-70. [ 韩卓汝, 赵志忠, 袁建平等. 海南岛北部红树林湿地表层沉积物重金属元素 分布相关特征及其污染源分析. 海南师范大学学报: 自然科学版, 2013, 26(1) : 66-70.]

[39] Yan XC, Yang XW, Huang XQ et al. Distribution and risk assessment of heavy metals in the surface estuarine sediments of main inflow rivers in Taihu Lake. Ecology and Environmental Sciences, 2016, 25(9): 1515-1521. [间兴成, 杨晓薇, 黄 烯茜等. 太湖主要人湖河口表层沉积物重金属分布特征及风险评价. 生态环境学报, 2016, 25(9): 1515-1521.]

[40] Liu EF, Shen J, Zhu YX et al. Heavy metals and nutrients pollution in sediments of Taihu Lake. Acta Sedimentologica Sin$i c a, 2004,22$ (3) : 507-512. [刘恩峰, 沈吉, 朱育新等. 太湖沉积物重金属及营养盐污染研究. 沉积学报, 2004, $22(3): 507-512$.

[41] Gu GX, Ni LX, Rong SY et al. Effects of cyanobacteria decomposition on the migration and transformation of heavy metals in sediment in Taihu Lake. Environmental Science and Technology, 2019, 32(1): 12-19. [ 顾国秀, 倪利晓, 荣诗怡等. 太湖蓝藻腐解过程对沉积物重金属迁移转化影响. 环境科技, 2019, 32(1) : 12-19.]

[42] Jiang J, Li YC, Wang N et al. Effect of cyanobacteria aggregation on the migration and release of heavy metals in Lake Chaohu. J Lake Sci, 2017, 29(3) : 558-566. DOI: 10.18307/2017.0304. [ 江江, 李玉成, 王宁等. 巢湖蓝藻聚集对重 金属迁移释放的影响. 湖泊科学, 2017, 29(3) : 558-566.]

[43] Shan YS, Shen AC, Liu C. Discussions on bottom mud dredging of the Taihu Lake. China Water Resources, 2018, (23): 11-13. [单玉书，沈爱春，刘畅. 太湖底泥清淤疏浚问题探讨. 中国水利, 2018，(23): 11-13.]

[44] Shen J, Yuan HZ, Liu EF et al. Spatial distribution and stratigraphic characteristics of surface sediments in Taihu Lake, China. Chinese Science Bulletin, 2010, 55(36): 3516-3524. [沈吉, 袁和忠, 刘恩峰等. 太湖表层沉积物的空间分布 与层序特征分析. 科学通报, $2010, \mathbf{5 5}(36): 3516-3524$. ] 